\title{
Errors in Medical Interpretation and Their Potential Clinical Consequences in Pediatric Encounters
}

\author{
Glenn Flores, MD*; M. Barton Laws, PhD\|; Sandra J. Mayo, EdM\|; Barry Zuckerman, MDł;

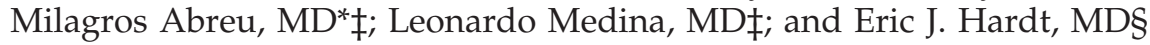

\begin{abstract}
Background. About 19 million people in the United States are limited in English proficiency, but little is known about the frequency and potential clinical consequences of errors in medical interpretation.

Objectives. To determine the frequency, categories, and potential clinical consequences of errors in medical interpretation.

Methods. During a 7-month period, we audiotaped and transcribed pediatric encounters in a hospital outpatient clinic in which a Spanish interpreter was used. For each transcript, we categorized each error in medical interpretation and determined whether errors had a potential clinical consequence.
\end{abstract}

Results. Thirteen encounters yielded 474 pages of transcripts. Professional hospital interpreters were present for 6 encounters; ad hoc interpreters included nurses, social workers, and an 11-year-old sibling. Three hundred ninety-six interpreter errors were noted, with a mean of 31 per encounter. The most common error type was omission (52\%), followed by false fluency $(16 \%)$, substitution (13\%), editorialization $(10 \%)$, and addition $(8 \%)$. Sixty-three percent of all errors had potential clinical consequences, with a mean of 19 per encounter. Errors committed by ad hoc interpreters were significantly more likely to be errors of potential clinical consequence than those committed by hospital interpreters (77\% vs $53 \%)$. Errors of clinical consequence included: 1) omitting questions about drug allergies; 2) omitting instructions on the dose, frequency, and duration of antibiotics and rehydration fluids; 3 ) adding that hydrocortisone cream must be applied to the entire body, instead of only to facial rash; 4) instructing a mother not to answer personal questions; 5 ) omitting that a child was already swabbed for a stool culture; and 6) instructing a mother to put amoxicillin in both ears for treatment of otitis media.

Conclusions. Errors in medical interpretation are common, averaging 31 per clinical encounter, and omissions are the most frequent type. Most errors have potential clinical consequences, and those committed by ad hoc interpreters are significantly more likely to have potential clinical consequences than those committed by hospital inter-

From the *Center for the Advancement of Urban Children, Department of Pediatrics, Medical College of Wisconsin, Milwaukee, Wisconsin; Departments of $\ddagger$ Pediatrics and §Internal Medicine, Boston University School of Medicine, Boston, Massachusetts; and ||Latino Health Institute, Boston, Massachusetts.

Presented in part at the annual meeting of the Pediatric Academic Societies; May 2, 1999; San Francisco, CA.

Received for publication Jan 29, 2002; accepted May 24, 2002.

Reprint requests to (G.F.) Center for the Advancement of Urban Children, Department of Pediatrics, 8701 Watertown Plank Road, Milwaukee, WI 53226. E-mail: gflores@mail.mcw.edu

PEDIATRICS (ISSN 0031 4005). Copyright $\odot 2003$ by the American Academy of Pediatrics. preters. Because errors by ad hoc interpreters are more likely to have potential clinical consequences, third-party reimbursement for trained interpreter services should be considered for patients with limited English proficiency. Pediatrics 2003;111:6-14; language, interpreters, medical errors, children, pediatrics, Hispanic Americans, quality.

ABBREVIATIONS. LEP, limited in English proficiency; SD, standard deviation.

ccording to the 2000 census, $\sim 45$ million peo-
ple in the United States speak a language
other than English at home, and $\sim 19$ million are limited in English proficiency (LEP). ${ }^{1}$ Five percent of school-aged US children (or $\sim 2.4$ million) are LEP, an $85 \%$ increase since $1979 .{ }^{2}$ Language barriers affect multiple aspects of health care for the LEP patient, including access to care, health status, and use of health services. ${ }^{3}$ Studies document that LEP patients often defer needed medical care, ${ }^{4}$ have a higher risk of leaving the hospital against medical advice, ${ }^{5}$ are less likely to have a regular health care provider, ${ }^{6}$ and are more likely to miss follow-up appointments, ${ }^{7}$ to be nonadherent with medications, ${ }^{7}$ and to be in fair/poor health. ${ }^{6}$

A medical interpreter is an essential component of effective communication between the LEP patient and the health care provider. Medical interpreters may be professional hospital interpreters employed by a health care institution, or ad hoc, untrained individuals, such as family members, friends, nonclinical hospital employees, and strangers from waiting rooms. Previous work has shown that family members $^{8}$ and untrained bilingual nurses ${ }^{9}$ who provide ad hoc interpretation can commit many errors of interpretation. Not enough is known, however, about the frequency and categories of medical interpreter errors that occur in clinical encounters, whether such errors potentially have clinical consequences, and if the use of hospital rather than ad hoc interpreters produces a higher quality of medical interpretation. The goals of this study, therefore, were to: 1) determine the frequency, categories, and potential clinical consequences of errors committed by medical interpreters; and 2) compare the quality of interpretation by professional hospital versus ad hoc interpreters.

\section{METHODS}

We audiotaped pediatric encounters in which a Spanish interpreter was used in the pediatric outpatient clinic of an urban 
Massachusetts hospital over a 7-month period. All study parents had identified themselves as LEP. A bilingual research assistant was present during the encounter only to record the interaction, and did not act as an interpreter, nor take part in subsequent production of transcripts or data analysis. A bilingual verbatim transcript was prepared from the audiotape of each encounter by a professional transcriptionist fluent in both English and Spanish. To ensure accuracy and reliability of the transcripts, each transcript was reviewed 3 times for errors, once by a bilingual physician whose first language is English (G.F.), a second time by a bilingual sociologist whose first language is English (M.B.L.), and a third time by a bilingual physician whose first language is Spanish (M.A.).

The encounters analyzed for this study represent all pediatric visits with Spanish interpreters that occurred in a larger study of patient-physician communication, which consisted of a convenience sample of 153 audiotaped visits in the pediatric outpatient clinics of an urban Massachusetts hospital. Of the 153 participants in this larger study, 110 of the children and their families were Latino. Among these 110 Latino participants, there were 74 mothers/adult caregivers who were LEP, for which 38 visits occurred in Spanish with Spanish-speaking clinicians, 13 visits included a Spanish interpreter, and 25 occurred in English without an interpreter. Although this larger study used a convenience sample, the sample was obtained to reflect a reasonable spectrum of outpatient pediatric visits experienced by Latino families, and has no obvious selection biases other than respondent refusal, which was rare (only 2 potential subjects refused to participate). Participants from the larger study were sampled to capture visits from the full range of daily office hours and all 5 clinic days (Monday-Friday) during the work week. Pediatric encounters included walk-in, sick, and routine health care maintenance visits at the pediatric primary care clinic, and initial and follow-up visits at the outpatient lead and failure-to-thrive clinics. Both pediatricians and pediatric nurse practitioners provided care to study patients, and patient care was in no way altered by the study, except for the presence of the research assistant and tape recorder. The patients and their families, clinicians, and interpreters were told only that this was a study of patient-physician communication, and they were not aware that errors of medical interpretation would be analyzed.

Personnel who provided medical interpretation were classified as: 1) hospital interpreters, professional interpreters (ie, those receiving financial compensation) employed by the study hospital's department of interpreter services; and 2) ad hoc interpreters, who could include family members, friends, nonclinical hospital employees, strangers from waiting rooms, and hospital clinical staff (including nurses and social workers) who had received no formal medical interpreter training or screening. During the period when the study was conducted, all Spanish hospital interpreters who had been hired had undergone some level of screening and evaluation for language proficiency in Spanish and English. There was, however, no ongoing training or formal performance evaluation in the hospital for interpreters. Low-intensity, voluntary formal interpreter training was sporadically available at various community sites, but it was not known what proportion of interpreters took advantage of these voluntary community opportunities.

For each audiotaped encounter, analysis consisted of identification of the frequency and categories of interpreter errors. An "interpreter error" was defined as any misinterpretation of an utterance that occurred in the clinical encounter, including those committed by the designated medical interpreter, as well as those made by health care providers (such as when a physician with limited Spanish proficiency made errors in Spanish while talking to the mother after the designated interpreter had departed). Errors by health care providers were classified as interpreter errors because the study focus was on errors of interpretation made by any staff member acting as a medical interpreter during a clinical encounter, and we found that certain providers often would attempt to interpret when the designated medical interpreter departed or was temporarily unavailable.

Five categories were used to classify interpreter errors, based on 4 categories used in previous work, ${ }^{10,11}$ supplemented by an additional category (false fluency). These categories are as follows:

Omission: The interpreter did not interpret a word/phrase uttered by the clinician, parent, or child.
Addition: The interpreter added a word/phrase to the interpretation that was not uttered by the clinician, parent, or child.

Substitution: The interpreter substituted a word/phrase for a different word/phrase uttered by the clinician, parent, or child.

Editorialization: The interpreter provided his or her own personal views as the interpretation of a word/phrase uttered by the clinician, parent, or child.

False Fluency: The interpreter used an incorrect word/phrase, or word/phrase that does not exist in that particular language.

In addition to being classified into 1 of these 5 categories, an interpreter error was also considered to have potential clinical consequences if it altered or potentially altered 1 or more of the following: 1) the history of present illness; 2) the past medical history; 3) diagnostic or therapeutic interventions; 4) parental understanding of the child's medical condition; or 5) plans for future medical visits (including follow-up visits and specialty referrals).

Medical jargon, idiomatic expressions, and contextual clarifications may occasionally require medical interpreters to not interpret a phrase word-for-word. Thus, any deviations from wordfor-word interpretation in transcripts that were attributable to jargon, idioms, or contextual clarifications were not classified as interpreter errors. Because medical interpreters may also act as a cultural broker or advocate, any utterances that could be interpreted as cultural explanations or patient or family advocacy were not classified as interpreter errors. A separate analysis of the relationship of the number of verbal exchanges, the interlocutor, and the quality of the interpretation will be reported elsewhere in a separate paper.

The validity of the analytic method for identification and classification of interpreter errors was assessed as follows: 2 transcripts (cases 26 and 153) were first subjected to preliminary error analysis using simple definitions of each error type and category. The 2 transcripts were scored by 3 observers, a bilingual physician whose first language is English (G.F.) and 2 bilingual physicians (M.A. and L.M.) whose first language is Spanish. To avoid the introduction of bias, the latter 2 observers were blinded to the study goals and hypotheses. Each of the observers was assessed as being highly fluent in their second language based on years of experience providing primary care to Spanish-speaking patients in a Pediatric Latino Clinic (G.F.), 7 years as a research associate on studies of English-speaking populations in the United States (M.A.), and years of teaching high school to English-speaking students in the Massachusetts school system (L.M.). Interobserver variability for the 3 observers was assessed using agreement matrices and by calculating the percentage of agreement in 2 separate analyses, 1 for overall interpreter errors, and the second only for errors of potential clinical consequence. The Kappa Index was also determined for errors of clinical consequence. It was not possible to derive a Kappa Index for overall errors, as transcripts could not be accurately scored for 1 of the 4 cells (cell d): when neither observer identified an error, there was no reliable way to determine whether one should count by words, phrases, transcript lines, or utterances.

The preliminary error analysis of the 2 test transcripts revealed a mean percentage of agreement ( \pm standard deviation [SD]) among the 3 observers on the overall errors of $60 \% \pm 19$, with a range of $31 \%$ to $82 \%$. Disagreements were primarily attributable to either overlooked errors or unintended differences in the line numbering of the transcripts analyzed by different observers. After line numbering corrections, refinements, and meeting for consensus purposes, there was complete agreement among the 3 observers on the number and type of overall interpreter errors. The mean percentage of agreement $( \pm \mathrm{SD})$ among the 3 observers on errors of potential clinical consequence in the preliminary analysis was $83 \% \pm 12$, with a range of $72 \%$ to $97 \%$. The mean $\kappa$ $( \pm$ SD) for errors of potential clinical consequence in the preliminary analysis was $0.57 \pm 0.3$ (considered a moderate strength of agreement by the guidelines of Landis and $K_{0 c h}{ }^{12}$ ), with a range of 0.21 to 0.97 (from fair to almost perfect agreement by the Landis and Koch guidelines ${ }^{12}$ ). Because the mean percentage of agreement and $\kappa$ were considered unacceptably low, the error categories and types were further refined. After refinement, there was mean agreement of $99 \% \pm 1.7$ (range: $97 \%-100 \%$ ) and a mean $\kappa$ of $0.99 \pm 0.03$ (range: $0.94-1.0$ [almost perfect by the Landis and Koch guidelines ${ }^{12}$ for both the mean and range]) regarding interpreter errors of potential clinical consequence on the 2 test transcripts. The remaining 11 transcripts were analyzed by the first 
author, using the refined error categories, types, and analytic approaches.

To analyze the statistical significance of differences between hospital and ad hoc interpreters in the proportion of errors made, the Yates-corrected $\chi^{2}$ test was used, with $P<.05$ considered statistically significant.

Institutional review board approval was obtained from the participating institution to conduct this study, and written informed consent was obtained from each participating parent.

\section{RESULTS}

Thirteen clinical encounters with Spanish interpreters present were audiotaped, yielding 6 hours of audiotapes, 474 pages of transcripts, and 49513 words that were exchanged. Hospital interpreters were present in 6 of 13 encounters; in the remaining 7 encounters, the ad hoc interpreters included a nurse for 3 encounters, a social worker for 3 encounters, and an 11-year-old sibling for 1 encounter. The number of words uttered per encounter averaged 3781 , and there was no statistically significant difference in the mean number of words uttered per encounter by interpreter type (mean words uttered $=$ 3919 when hospital interpreters were present vs 3663 when ad hoc interpreters were present, with $P>.5$ by the 2-tailed Student $t$ test). The visit type, clinician present, patient age, and number of interpreter errors in each clinical encounter are summarized in Table 1.

There were 396 interpreter errors noted in the 13 clinical encounters (Table 2). The mean number ( \pm standard error) of interpreter errors per clinical encounter was $30.5 \pm 3.6$, with a range of 10 to 60 . There was no statistically significant difference between hospital and ad hoc interpreters in the mean number of errors committed per clinical encounter.

The proportions of interpreter errors by category were: omission, $52 \%$; false fluency, $16 \%$; substitution, $13 \%$; editorialization, $10 \%$; and addition, $8 \%$. There were no statistically significant differences between hospital and ad hoc interpreters in the proportion of errors by specific category (Table 2), except for false fluency errors, which occurred more often during encounters with hospital than ad hoc interpreters (22\% vs $9 \%, P=.001)$. Additional analysis of false fluency errors occurring in encounters with hospital interpreters revealed that health care providers made $76 \%$ of the false fluency errors, and $58 \%$ of these errors occurred while the interpreter was out of the room or on the phone, whereas the remaining $42 \%$ of errors were made by the provider without any correction by the interpreter. Health care providers were $>11$ times more likely (relative risk: $11.4 ; 95 \%$ confidence interval: 1.7-76.2) to make false fluency errors when a hospital interpreter was involved, committing $76 \%$ of the false fluency errors with trained interpreters, compared with only $7 \%$ of false fluency errors when untrained interpreters were in-

TABLE 1. Selected Features of Study Encounters

\begin{tabular}{|c|c|c|c|c|c|c|c|}
\hline Case & Visit Type & Clinician Present & $\begin{array}{l}\text { Patient's } \\
\text { Age }\end{array}$ & $\begin{array}{l}\text { Interpreter } \\
\text { Type }\end{array}$ & $\begin{array}{c}\text { Interpreter's } \\
\text { Relationship to } \\
\text { Patient, if Ad Hoc } \\
\text { Interpreter }\end{array}$ & $\begin{array}{l}\text { No. of } \\
\text { Interpreter } \\
\text { Errors in } \\
\text { Encounter }\end{array}$ & $\begin{array}{c}\text { No. }(\%) \text { of } \\
\text { Interpreter Errors } \\
\text { of Potential } \\
\text { Clinical } \\
\text { Consequence in } \\
\text { Encounter }\end{array}$ \\
\hline 13 & $\begin{array}{l}\text { Well-child visit at } \\
\text { pediatric primary } \\
\text { care clinic }\end{array}$ & Nurse practitioner & $7 y$ & Hospital & - & 45 & $16(36 \%)$ \\
\hline 19 & $\begin{array}{l}\text { Sick visit at pediatric } \\
\text { primary care clinic }\end{array}$ & $\begin{array}{l}\text { Attending } \\
\text { pediatrician }\end{array}$ & $9 \mathrm{mo}$ & Ad hoc & Nurse & 10 & $9(90 \%)$ \\
\hline 24 & $\begin{array}{l}\text { Sick visit at pediatric } \\
\text { primary care clinic }\end{array}$ & $\begin{array}{l}\text { Nurse practitioner } \\
\text { and attending } \\
\text { pediatrician }\end{array}$ & $1 \mathrm{mo}$ & Hospital & - & 44 & $29(66 \%)$ \\
\hline 26 & $\begin{array}{l}\text { Sick visit at pediatric } \\
\text { primary care clinic }\end{array}$ & Pediatric resident & $2 y$ & Ad hoc & 11-year-old sibling & 58 & $49(84 \%)$ \\
\hline 77 & $\begin{array}{l}\text { Sick visit at pediatric } \\
\text { primary care clinic }\end{array}$ & $\begin{array}{l}\text { Attending } \\
\text { pediatrician }\end{array}$ & $2 \mathrm{mo}$ & Ad hoc & Nurse & 24 & $20(83 \%)$ \\
\hline 83 & $\begin{array}{l}\text { Sick visit at pediatric } \\
\text { primary care clinic }\end{array}$ & $\begin{array}{l}\text { Attending } \\
\text { pediatrician }\end{array}$ & $8 \mathrm{mo}$ & Ad hoc & Nurse & 18 & $12(66 \%)$ \\
\hline 84 & $\begin{array}{l}\text { Follow-up at failure } \\
\text { to thrive clinic }\end{array}$ & $\begin{array}{l}\text { Attending } \\
\text { pediatrician }\end{array}$ & $12 \mathrm{mo}$ & Ad hoc & Social worker & 21 & $13(62 \%)$ \\
\hline 88 & $\begin{array}{l}\text { Walk-in for } \\
\text { immunizations at } \\
\text { pediatric primary } \\
\text { care clinic }\end{array}$ & $\begin{array}{l}\text { Attending } \\
\text { pediatrician }\end{array}$ & $7 y$ & Hospital & - & 14 & $5(36 \%)$ \\
\hline 106 & $\begin{array}{l}\text { Follow-up at failure } \\
\text { to thrive clinic }\end{array}$ & $\begin{array}{l}\text { Attending } \\
\text { pediatrician }\end{array}$ & $11 \mathrm{mo}$ & Ad hoc & Social worker & 24 & $16(67 \%)$ \\
\hline 120 & $\begin{array}{l}\text { Follow-up at failure } \\
\text { to thrive clinic }\end{array}$ & $\begin{array}{l}\text { Attending } \\
\text { pediatrician }\end{array}$ & $13 \mathrm{mo}$ & Ad hoc & Social worker & 10 & $8(80 \%)$ \\
\hline 153 & $\begin{array}{l}\text { Well-child visit at } \\
\text { pediatric primary } \\
\text { care clinic }\end{array}$ & Nurse practitioner & $5 y$ & Hospital & - & 45 & $23(51 \%)$ \\
\hline 165 & $\begin{array}{l}\text { Well-child visit at } \\
\text { pediatric primary } \\
\text { care clinic }\end{array}$ & Nurse practitioner & $7 y$ & Hospital & - & 23 & $16(70 \%)$ \\
\hline 176 & $\begin{array}{l}\text { Initial visit to lead } \\
\text { clinic }\end{array}$ & $\begin{array}{l}\text { Attending } \\
\text { pediatrician }\end{array}$ & $18 \mathrm{mo}$ & Hospital & - & 60 & $34(57 \%)$ \\
\hline
\end{tabular}




\begin{tabular}{ccccccc}
\hline \multirow{2}{*}{$\begin{array}{c}\text { Interpreter } \\
\text { Type }\end{array}$} & Omission & Substitution & Addition & Editorialization & False Fluency & $\begin{array}{c}\text { No. (\%) Errors } \\
\text { of Potential Clinical } \\
\text { Consequence }\end{array}$ \\
\cline { 2 - 5 } $\begin{array}{c}\text { Total } \\
\text { Errors }\end{array}$ \\
\hline $\begin{array}{c}\text { Hospital } \\
(N=6)\end{array}$ & $117(51 \%)$ & $27(12 \%)$ & $17(7 \%)$ & $20(9 \%)$ & $50\left(22 \%^{*}\right)$ & $123(53 \% \dagger)$ \\
$\begin{array}{c}\text { Ad hoc } \\
(N=7)\end{array}$ & $90(55 \%)$ & $26(16 \%)$ & $15(9 \%)$ & $19(12 \%)$ & $15\left(9 \%^{*}\right)$ & $127(77 \%+)$ \\
Totals & $207(52 \%)$ & $53(13 \%)$ & $32(8 \%)$ & $39(10 \%)$ & $65(16 \%)$ & 165 \\
\hline
\end{tabular}

${ }^{*} P=.007$ by Yates-corrected $\chi^{2}$ test for comparison between hospital versus ad hoc interpreters.

$+P<.001$ by Yates-corrected $\chi^{2}$ test for comparison between hospital versus ad hoc interpreters

volved $(P<.001)$. Nevertheless, health care providers committed only $\sim 10 \%$ of all errors observed in this study. About three quarters (73\%) of the false fluency errors committed by hospital interpreters involved medical terminology, including not knowing the correct Spanish words for "level," "results," and "medicine," and using the Puerto Rican colloquialism for mumps, which could not be understood by a Central American mother.

There were 250 errors (63\% of all errors) that had potential clinical consequences (Table 2). The mean number ( \pm standard error) of errors with potential clinical consequences per encounter was $19 \pm 3.2$, with a range of 5 to 49 . Errors made by ad hoc interpreters were significantly more likely to have potential clinical consequences than those made by hospital interpreters, at $77 \%$ vs $53 \%(P<.0001)$. When an 11-year-old sibling was used as an interpreter, for example, $84 \%$ of the 58 errors she committed had potential clinical consequences, and when an untrained staff nurse interpreted, $90 \%$ of his 10 errors had potential clinical consequences. Indeed, the lowest proportion of errors of potential clinical consequence committed by an ad hoc interpreter was $62 \%$.

Interpreter errors of potential clinical consequence included: 1) omitting questions about drug allergies; 2) omitting key information about the past medical history (a mother's statement that her child had been hospitalized at birth for a renal infection); 3) omitting crucial information about the chief complaint and other important symptoms (Fig 1); 4) omitting instructions about antibiotic dose, frequency, and duration; 5) instructing a mother to give an antibiotic for 2 instead of 10 days (Fig 2); 6) erroneously adding that hydrocortisone cream must be applied to an infant's entire body, instead of solely to a facial rash (Fig 3); 7) telling a mother to give soy formula to her infant, instead of a physician's instructions to breastfeed only; 8) omitting instructions on the amount, frequency, and type of rehydration fluids for gastro-

Pediatrician: "So [he vomited] five times between 1:00 and 3:00? And after that he hasn't

thrown up?

Interpreter: "Que si desde eso él no ha vomitado?"

Mother: "No. Ahora tiene como dolor de oido y eso."

Interpreter: "Yes, he havin' pain"

Mother: "Dile que él tiene algo en la boca.

Dile."

[SILENCE]

Pediatrician: "How old is he now?"
"That if since that [time] he has not vomited?"

"No. Now he has like pain in the ear and so on." "Tell her [the pediatrician] that he has something on his mouth. Tell her."

\section{Interpreter: "Three."}

Fig 1. Multiple omission errors of potential clinical consequence committed by an ad hoc interpreter (the patient's 11-year-old sister) during a sick visit to a pediatrician by a 2 -year-old child for vomiting and dehydration (case 26). Note that the pediatrician never receives a response about how many times the child has vomited before the visit, and the interpreter omits the mother's statements about the child's ear pain and oral lesion. 
Pediatrician: "So probably this rash is from the Augmentin."

Interpreter: "Probablemente, es de la

medicina, por eso va a cambiarla. Y ahora ella

puede comenzar a tomar otra medicina, por

dos dias. What else did you want me to tell

her?"
"Probably, it's from the medicine, and

therefore she's going to change it. And now

she can start to take another medicine, for two

days. What else did you want me to tell her?"

Pediatrician: "Ten days on the new medicine. Don't give the old medicine anymore. Plenty to

drink. Treat the fever."

Interpreter: "Okay. Dice que no toma la

medicina, la otra medicina, $y$... es importante

que ella bebe bastante , ¿ ¿tiene Tylenol?"
"Okay. She says that she isn't taking the medicine, the other medicine, and ... it's

important that she drink enough, and, do you

have Tylenol?"

Fig 2. Substitution, addition, and omission errors of potential clinical consequence committed by an ad hoc interpreter during a sick visit to a pediatrician by a 9-month-old child for fever, vomiting, and a rash (case 19).

enteritis; 9) editorializing to a mother that she should not answer personal questions asked by her physician about sexually transmitted diseases and drug use; 10) explaining that an antibiotic was being prescribed for the flu; 11) omitting a mother's clear explanation that a child had already been swabbed rectally for a stool culture; 12) omitting and substituting for a mother's description of her child's abnormal behavioral symptoms (Fig 4); and 13) instructing a mother to put oral amoxicillin into her child's ears to treat otitis media (Fig 5).

\section{DISCUSSION}

Implications for Practice, Training, and Research

Errors in medical interpretation were found to be alarmingly common in this study, averaging $\sim 31$ per clinical encounter. In addition, there was no statistically significant difference between hospital and ad hoc interpreters in the mean number of errors committed per encounter. Although errors made by hospital interpreters were significantly less likely to be of potential clinical consequence than those made by ad hoc interpreters, over half of hospital interpreter errors had potential clinical consequences. These findings support the conclusion that most hospital interpreters do not receive adequate training at their institution. ${ }^{13}$ Fewer than one fourth of hospitals nationwide provide any training for medical interpreters. ${ }^{13}$ Only $14 \%$ of US hospitals provide training for volunteer interpreters, and in half of these hospitals, the training programs are not mandatory. ${ }^{13}$ Even when hospitals provide training to medical interpreters, the training may be limited to short orientation sessions or shadowing more seasoned interpreters. ${ }^{13}$ Our study findings and these national data suggest that additional research and policy work is needed to determine what type of medical interpreter training is most effective in reducing interpreter errors. Specific issues that need to be addressed include whether training of medical interpreters should be mandatory, and which training approaches are most effective in eliminating common errors of potential clinical consequence and in improving accuracy and understanding medical terminology.

The categories of interpreter errors noted in this study indicate areas where more training is needed for medical interpreters. Omissions by far were the most common type of interpreter error, accounting for more than half of all errors. This finding suggests that a principal focus of interpreter training should be the faithful transmission of each and every utterance by clinicians, patients, and patients' families. 
Nurse Practitioner: "And then what I'm going to do is give mom an ointment. It's a steroid ointment to put on the baby's face two times a day just for three or four days, and then stop. I want her to use hydrocortisone cream, okay? Twice a day."

Interpreter: "Esa crema también se la pasas por el cuerpo, la que te van a escribir ahi." Esa se la puedes comprar en la tienda, en la farmacia."

Nurse Practitioner: "She's going to put this on twice a day, just for three or four days."
"That cream also you put on his body, that which they're going to write for you there. That you can buy in the store, in the pharmacy."

Interpreter: "En cuatro días, okay?" "In four days, okay?

Fig 3. Multiple errors of omission and substitution of potential clinical consequence committed by a hospital interpreter during a sick visit to a pediatric nurse practitioner by a 1-month-old male infant for seborrhea and an upper respiratory illness.

Pediatrician: "In the past four months, how has he been doing?"

Interpreter: "Los últimos cuatro meses, ¿cómo sigue él?"
"The last 4 months, how has he been doing?"

"He's gotten like that, dizzy, completely pale, and he's been trying to bite."
Mother: "Se ponía así mareado, todo pálido, y trataba de morder."


Nurse Practitioner: "And she's going to have 1 teaspoon 3 times a day for 10 days."

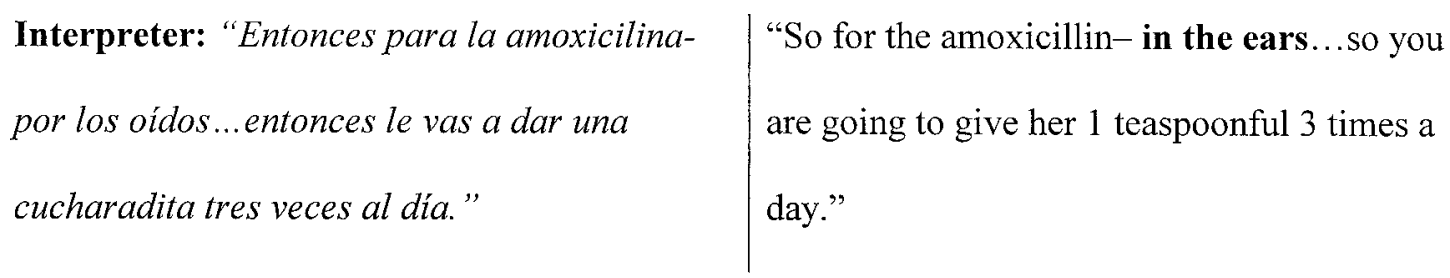

Fig 5. Addition and omission errors of clinical consequence made by an ad hoc interpreter during a visit to a pediatric nurse practitioner by a 7-year-old-girl diagnosed with otitis media (case 165).

means of quality improvement for medical interpreter services, indicating when additional training in medical terminology is needed.

The categories of interpreter errors noted in this study also indicate that more training is needed for clinicians in the use of medical interpreters. Clinicians commit most false fluency errors when the interpreter leaves the room or is taking a telephone call, and clinicians are 11 times more likely to make false fluency errors when hospital interpreters participate in the clinical encounter. These findings are consistent with studies that show that most hospital staff receive no training on working with interpreters, ${ }^{13}$ and most medical schools do not provide adequate instruction on linguistic and cultural issues in clinical care. ${ }^{14}$ For example, only $23 \%$ of US hospitals provide any training for their staff on the use of medical interpreters, and such training may consist of nothing more than policies and procedures for requesting interpreters. ${ }^{13}$ These studies and our results suggest that clinicians should receive skills training on the proper technique for working with medical interpreters, especially the risk of false fluency errors associated with clinicians with limited foreign language fluency. It is recommended that interchanges between such clinicians and patients (and their families) in a foreign language should be limited to when the medical interpreter is present and not distracted; if such interchanges occur without an interpreter, the clinician should consider repeating the interchange when the interpreter is available once again. The limited foreign language skills of a clinician can prove to be an asset, however, in that they can provide a means of verifying the quality of medical interpretation. For example, if the clinician hears a patient utter a word or phrase that was not translated by the interpreter, the clinician could bring this to the interpreter's attention, and reemphasize the importance of faithful message transmission of each and every utterance. Conversely, because $42 \%$ of false fluency errors committed by clinicians occurred in the presence of an interpreter and went uncorrected, medical interpreters probably should be taught that it is reasonable and appropriate to correct clinician false fluency errors.

\section{Medical Errors and Quality of Care}

The study findings suggest that interpreter errors of potential clinical consequence could be a previ- ously unrecognized possible root cause of medical errors. Although a recent Institute of Medicine report ${ }^{15}$ has drawn much attention to medical errors, errors of medical interpretation have not generally been included in the discussion of sources of medical errors. In this study, several documented common mechanisms for medical errors ${ }^{16,17}$ were observed among the interpreter errors of clinical consequence, including being told to use the wrong dose, frequency, duration or mode of administration of drugs and other therapeutic interventions, and omitting relevant clinical information on drug allergies and the past medical history. These findings suggest that for LEP patients, providing qualified, trained medical interpreters may be an important means of reducing medical errors and improving the quality of medical care. It also seems reasonable that as part of ongoing quality improvement efforts, medical institutions might consider periodically audiotaping or videotaping a representative subsample of clinical encounters where medical interpreters are used, to identify and monitor the overall number and categories of interpreter errors, the number of interpreter errors of potential clinical consequence, and medical errors that result from interpreter errors.

\section{Study Limitations}

Several limitations of this study should be noted, along with their implications for future research. Our sample size was relatively small; studies of errors of medical interpretation on a larger scale are needed. Only 1 observer analyzed 11 of the transcripts, so interpreter errors potentially may have been missed that could have been identified had multiple observers analyzed these transcripts. Single-observer transcript analysis was performed, however, only after refinements of the analytic technique were instituted as a result of multiple-observer testing and validation. It also seems unlikely that identification and inclusion of potentially overlooked errors would have substantially altered the principal study findings, but additional study of this interpreter error analytic tool is warranted. This study was limited to pediatric encounters; similar studies of adult LEP populations need to be conducted, particularly given that interpreter errors may have an even greater effect on adults because of their generally greater morbidity, comorbidity, and mortality. Similarly, we examined only outpatient encounters with Spanish 
interpreters, and studies are needed of interpreter errors and their clinical consequences in other languages and in the emergency department and inpatient settings. The hospital interpreters in this study had little to no training (although the study institution has subsequently initiated extensive training of their hospital interpreters). Replication of this study with hospital interpreters who have received extensive, consistent training compared with ad hoc interpreters may reveal more substantial differences in the number and categories of errors. Because LEP patients who need interpreters sometimes obtain medical care without interpreters, more research is needed comparing health care quality and satisfaction with care when LEP patients have trained hospital versus ad hoc versus no interpreters.

\section{Policy Implications}

The study finding that errors made by ad hoc interpreters are significantly more likely to have potential clinical consequences-coupled with a fairly extensive literature documenting that LEP patients tend to receive poorer quality medical care-would seem to constitute a strong argument for third-party reimbursement for trained medical interpreter services. Studies demonstrate a wide range of adverse effects that limited English proficiency can have on health and use of health services, including impaired health status,, 18 a lower likelihood of having a usual source of medical care, $6,18,19$ lower rates of mammograms, pap smears, and other preventive servic$\mathrm{es}^{20,21}$ nonadherence with medications, ${ }^{7}$ a greater likelihood of a diagnosis of more severe psychopathology and leaving the hospital against medical advice among psychiatric patients,, 22 a lower likelihood of being given a follow-up appointment after an emergency department visit, ${ }^{23}$ an increased risk of intubation among children with asthma, ${ }^{24}$ a greater risk of hospital admissions among adults, ${ }^{25}$ an increased risk of drug complications, ${ }^{26}$ longer medical visits, ${ }^{27,28}$ higher resource utilization for diagnostic testing, ${ }^{28}$ lower patient satisfaction, ${ }^{18,29,30}$ and impaired patient understanding of diagnoses, medications, and follow-up. ${ }^{31,32}$ Latino parents consider the lack of interpreters and Spanish-speaking staff to be the greatest barriers to health care for their children, and 1 out of every 17 parents in one study reported not bringing their child in for needed medical care because of these language issues. ${ }^{4}$ On the other hand, recent studies indicate that trained professional medical interpreter services are associated with improvements in the delivery of health care services to LEP patients, ${ }^{33}$ but do not increase the mean duration of medical visits. ${ }^{34}$

The lack of trained hospital interpreters is not uncommon for the millions of LEP patients in the United States: one study found that no interpreter was used for $46 \%$ of LEP patients, and when an interpreter was used, 39\% had no training. ${ }^{31}$ In a guidance memorandum, the Office of Civil Rights stated that the denial or delay of medical care for LEP patients because of language barriers constitutes a form of discrimination, and requires that any recipient of Medicaid or Medicare must provide ade- quate language assistance to LEP patients. ${ }^{35}$ A Presidential Executive Order also has been issued on improving access to services for persons with Limited English Proficiency. ${ }^{36}$ Concerns have been raised by medical associations about physicians having to cover the costs of complying with the Office of Civil Rights guidance memorandum, ${ }^{37}$ but the issue could be resolved by having third-party reimbursement for interpreter services. Although additional research on the cost effectiveness of third-party reimbursement for interpreter services would be helpful, mounting evidence suggests that additional studies of the issue may not be needed, including a successful \$71 million lawsuit over a misinterpreted word in the emergency department, ${ }^{38}$ a report of a prolonged hospitalization for perforated appendicitis that might have been avoided if an interpreter had been called, ${ }^{39}$ and a report of children placed in state custody for mistaken child abuse because of a misinterpreted word and failure to initially call an interpreter. ${ }^{39}$ Legal liability and medical errors may be important factors in considering whether investment in third-party reimbursement of interpreter services is a reasonable strategy for assuring that LEP patients receive high-quality, equitable care.

\section{ACKNOWLEDGMENTS}

This study was supported in part by the Generalist Physician Faculty Scholars Program (to Dr Flores), the Minority Medical Faculty Development Program (to Dr Flores), and the Opening Doors Program (to Dr Laws) of the Robert Wood Johnson Foundation. Dr Flores is a recipient of an Independent Scientist (K02) Award from the Agency for Healthcare Research and Quality.

We thank Howard Bauchner and Paul Wise for their comments on earlier manuscript drafts.

\section{REFERENCES}

1. US Census Bureau. QT-02. Profile of Selected Social Characteristics: 2000. Available at: http://factfinder.census.gov/servlet/QTTable?ds_ name $=$ ACS_C2SS_EST_G00_\&geo_id $=01000 U S \& q r \_n a m e=A C S \_C 2 S S$ EST G00_QT02. Accessed November 7, 2002

2. Federal Interagency Forum on Child and Family Statistics. America's Children: Key National Indicators of Well-Being. Available at: http:// www.nichd.nih.gov/publications/pubs/americaschildren2000.pdf

3. Flores G. Culture and the patient-physician relationship: achieving cultural competency in health care. J Pediatr. 2000;136:14-23

4. Flores G, Abreu M, Olivar MA, Kastner B. Access barriers to health care for Latino children. Arch Pediatr Adolesc Med. 1998;152:1119-1125

5. Alpert M, Kesselman M, Marcos L, Urcuyo L. The language barrier in evaluating Spanish-American patients. Arch Gen Psychol. 1973;29: 655-659

6. Kirkman-Liff B, Mondragón D. Language of interview: relevance for research of southwest Hispanics. Am J Public Health. 1991;81:1399-1404

7. Manson A. Language concordance as a determinant of patient compliance and emergency room use in patients with asthma. Med Care. 1988;1119-1128

8. Ebden P, Bhatt A, Carey OJ, Harrison B. The bilingual consultation. Lancet. 1988;13:347

9. Elderkin-Thompson V, Silver RC, Waitzkin H. When nurses double as interpreters: a study of Spanish-speaking patients in a US primary care setting. Soc Sci Med. 2001;52:1343-1358

10. Barik H. Simultaneous interpretation: temporal and quantitative data [PhD dissertation]. Chapel Hill, NC: University of North Carolina, Chapel Hill; 1972

11. Hornberger JC, Gibson CD Jr, Wood W, et al. Eliminating language barriers for non-English-speaking patients. Med Care. 1996;34:845-856

12. Landis RJ, Koch GG. The measurement of observer agreement for categorical data. Biometr. 1977;33:159-174

13. Ginsberg C, Martin V, Andrulis D, Shaw-Taylor Y, McGregor C. Interpretation and Translation Services in Health Care: A Survey of US Public and 
Private Teaching Hospitals. Washington, DC; National Public Health and Hospital Institute; 1995:1-49

14. Flores G, Gee D, Kastner B. The teaching of cultural issues in US and Canadian medical schools. Acad Med. 2000;75:451-455

15. Kohn LT, Corrigan JM, Donaldson MS, eds. To Err is Human: Building a Safer Health System. Washington, DC: National Academy Press; 2000

16. Thomas EJ, Studdert DM, Burstin HR, et al. Incidence and types of adverse events and negligent care in Utah and Colorado. Med Care. 2000;38:261-271

17. Weingart SN, Wilson RM, Gibberd RW, Harrison B. Epidemiology of medical error. BMJ. 2000;320:774-777

18. Hu DJ, Covell RM. Health care usage by Hispanic outpatients as a function of primary language. West J Med. 1986;155:490-493

19. Weinick RM, Krauss NA. Racial/ethnic differences in children's access to care. Am J Public Health. 2000;90:1771-1774

20. Marks G, Solis J, Richardson JL, Collins LM, Birba L, Hisserich J. Health behavior of elderly Hispanic women: does cultural assimilation make a difference? Am J Public Health. 1987;77:1315-1319

21. Woloshin S, Schwartz L, Katz SJ, Welch HG. Is language a barrier to the use of preventive services? J Gen Intern Med. 1997;12:472-477

22. Baxter M, Bucci W. Studies in linguistic ambiguity and insecurity. Urban Health. 1981;June:36-40

23. Sarver J, Baker DW. Effect of language barriers on follow-up appointments after an emergency department visit. J Gen Intern Med. 2000;15: 256-264

24. LeSon S, Gershwin ME. Risk factors for asthmatic patients requiring intubation. I. Observations in children. J Asthma. 1995;32:285-294

25. Lee ED, Rosenberg CR, Sixsmith DM, Pang D, Abularrage J. Does a physician-patient language difference increase the probability of hospital admission? Acad Emerg Med. 1998;5:86-89

26. Gandhi TK, Burstin HR, Cook EF, Puopolo AL, Haas JS, Brennan TA, Bates DW. Drug complications in outpatients. J Gen Intern Med. 2000; 15:149-154
27. Kravitz RL, Helms LJ, Azari R, Antonius D, Melnikow J. Comparing the use of physician time and health care resources among patients speaking English, Spanish, and Russian. Med Care. 2000;38:728-738

28. Hampers LC, Cha S, Gutglass DJ, Binns HJ, Krug SE. Language barriers and resource utilization in a pediatric emergency department. Pediatrics. 1999;103:1253-1256

29. Carrasquillo O, Orav EJ, Brennan TA, Burstin HR. Impact of language barriers on patient satisfaction in an emergency department. J Gen Intern Med. 1999;14:82-87

30. Morales LS, Cunningham WE, Brown JA, Liu H, Hays RD. Are Latinos less satisfied with communication by health care providers? J Gen Intern Med. 1999;14:409-417

31. Baker DW, Parker RM, Williams MV, et al. Use and effectiveness of interpreters in an emergency department. JAMA. 1996;275:783-788

32. Crane JA. Patient comprehension of doctor-patient communication on discharge from the emergency department. J Emerg Med. 1997;15:1-7

33. Jacobs EA, Lauderdale DS, Meltzer D, Shorey JM, Levinson W, Thisted RA. Impact of interpreter services on delivery of health care to limitedEnglish-proficient patients. J Gen Intern Med. 2001;16:468-474

34. Tocher TM, Larson EB. Do physicians spend more time with nonEnglish speaking patients? J Gen Intern Med. 1999;14:303-309

35. Hayashi D. Guidance memorandum. January 29, 1998. Title VI prohibition against national origin discrimination-persons with limitedEnglish proficiency. http://www.hhs.gov/progorg/ocr/lepfinal.htm

36. President William J Clinton. Executive Order: Improving Access to Services for Persons with Limited English Proficiency. August 11, 2000

37. Landers SJ. Doctors resent being forced to find, pay for interpreters. http://www.ama-assn.org/sci-pubs/amnews/pick_00/gvsa1120.htm

38. Harsham P. A misinterpreted word worth $\$ 71$ million. Med Econ. 1984; June:289-292

39. Flores G, Abreu M, Schwartz I, Hill MD. The importance of language and culture in pediatric care: case studies from the Latino community. J Pediatr. 2000;137:842-848

\section{COLLEGE STUDENTS AND THE INTERNET}

"The report, 'The Internet Goes to College: How Students Are Living in the Future With Today's Technology,' was produced by the Pew Internet and American Life Project in Washington, and provides a snapshot of an emerging young digital class.

One fifth of today's college students began using computers from the ages of 5 to 8 , the authors state, and an overwhelming $86 \%$ of them had gone online compared with $59 \%$ of the general population; $72 \%$ check e-mail messages at least once a day... Nearly $75 \%$ of college students say they use the Internet more than they use the library to look for information; just $9 \%$ said they used the library more."

Schwartz J. New York Times. September 16, 2002

Noted by JFL, MD 